\title{
Research on Deformation Characteristics and Control Technology of Soft Rock Roadway under Dynamic Disturbance
}

\author{
Chuan-Wei Zang (D), Yang Chen, Miao Chen (D), Hong-Mo Zhu, \\ Chen-Ming Qu, and Jia Zhou \\ College of Energy and Mining Engineering, Shandong University of Science and Technology, Qingdao, Shandong 266590, China \\ Correspondence should be addressed to Miao Chen; miaochen@sdust.edu.cn
}

Received 8 October 2020; Revised 24 January 2021; Accepted 22 February 2021; Published 8 March 2021

Academic Editor: Alvaro Cunha

Copyright ( 92021 Chuan-Wei Zang et al. This is an open access article distributed under the Creative Commons Attribution License, which permits unrestricted use, distribution, and reproduction in any medium, provided the original work is properly cited.

\begin{abstract}
In the mining process of an underground coal mine, the dynamic load often causes great damage to the roadway and affects the normal mining of coal mine. In this paper, the deformation of surrounding rocks under static load and different disturbance intensities is studied by numerical simulation. The results show that under the same static load condition, the greater the dynamic load strength is, the more obvious the roadway roof displacement subsidence is. With the increase in dynamic load propagation distance, the amplitude of the dynamic load waveform decreases gradually. Under the same disturbance load intensity, the variation of roadway displacement with different disturbance load frequencies is studied. According to the influence of dynamic load on the deformation of the roadway, a combined support plan of shotcrete anchor net and reinforcement anchor cable is proposed. Finally, the rationality of the optimized support scheme is verified by numerical simulation and field results. The results show that the combined support scheme can effectively increase the strength of the broken soft rock and reduce the deformation of the surrounding rock. At the same time, it releases the expansion energy generated by the mutual compression and deformation of the rock layers, effectively maintaining the long-term stability of the roadway.
\end{abstract}

\section{Introduction}

The soft rock roadway support has always been a difficult problem for coal mining in China [1]. With the increase in mining depth, roadway deformation is very serious under the influence of strong disturbance. Besides, due to the influence of mining disturbance and artificial blasting, the traditional single support method cannot deal with a series of problems such as high stress and strong disturbance in the deep. Therefore, it is significant to study the mechanical properties of coal and rock under various disturbance loads and put forward an effective optimal support scheme.

To solve the problem of the large deformation of a strongly disturbed roadway, many scholars have done much research. Duan et al. [2] studied the stress distribution of surrounding rock and the propagation mode of stress waves during blasting. To prevent large deformations of deep soft rock roadways, Guo et al. [3] proposed a combined support technology consisting of constant resistance large deformation bolts, steel strips, and grouting bolt pipes. Qi et al. [4] proposed the bearing strength theory of a superimposed arch under the condition of "anchor spray net + anchor cable" combined support for deep weak surrounding rock. Pandit et al. [5] used DDS technology to study the dynamic response of roadway roof bolts under cyclic blasting loads and the influence of cyclic blasting loads on the roof surrounding rock. Given the difficulty of studying the failure process of underground rock, an experimental method to explore the dynamic failure process of a circular diamond prestressed rock sample was proposed $[6,7]$. Chen et al. [8] found that the asymmetric deformation of a roadway is caused by a change in the magnitude and direction of the stress field of the surrounding rock caused by the mining stress. He et al. [9] and Zhang et al. [10] analyzed the failure and instability mechanism of roadway affected by mining in adjacent large fully mechanized top coal caving face and proposed the supporting technology of high prestressed truss anchor cable. Based on the analysis of the 
plastic zone theory, Zhang et al. [11] pointed that the range and shape of the plastic zone of the surrounding rock were the theoretical basis for the quantitative design of the supporting structure and proposed a support scheme for weak cemented soft rock roadways. Wang et al. [12] analyzed the deformation mechanism of the roadway, and the research results show that the main reason for the failure of the soft rock roadway is that the support scheme is unreasonable and the support form is improper, which cannot bear the deformation of soft rock roadway. Li et al. [13] analyzed the dynamic deformation and failure of surrounding rock under the action of blasting and a seismic dynamic load and expounded the dynamic failure process of rock mass in theory. Kang et al. [14] proposed that the use of ultra-high bolts with high initial anchoring force supplemented by grouting and energy release measures can maintain the stability of the deep roadway. The characteristics of vibration velocity, amplitude, and frequency are also studied by researchers [15-19], and the attenuation relationship of vibration velocity, the charge amount, distance from blasting site, and geological discontinuity is clarified. Wang et al. [20] studied the deformation characteristics of surrounding soft rock in the deep soft rock roadway and proposed a confined concrete support scheme to maintain the stability of the roadway. Wang et al. [21] proposed the integral support technology of segmented bolt grouting. Zhang et al. [22] studied the bearing mechanism of the double bearing structures in the deep soft rock roadway and regarded the surrounding rock of the broken roadway as a small supporting structure and the deep surrounding rock as a large bearing structure. Sun et al. [23] used numerical simulation to analyze the failure characteristics of asymmetrically deformed deep roadways in inclined rock strata and proposed coupling control strategies. Ramulu et al. [24] used the drilling camera to measure the cumulative damage effect of surrounding rock mass under the action of cyclic blasting. The results show that high-frequency vibration can cause damage to adjacent rock masses, while low-frequency vibration can cause long-distance rock mass damage. Chang et al. $[25,26]$ discussed the characteristics of roadway deformation, and they pointed out that high ground stress, mining stress, and low-strength rock are the cause of large deformation. Singh et al. [27] studied the impact damage of adjacent open-pit blasting to underground coal mines and strain and stress sensors arranged on the roof and pillars to monitor the vibration and deformation of the formation before and after multiple blasting. Taking into account the high overburden and tectonic stress, Shen [28] used the Universal Discrete Element Program (UDEC) to establish a detailed numerical model to analyze the stability and deformation of the soft rock roadway. Wang et al. [29] studied the deformation and failure mechanism of the surrounding rock of the roadway under the influence of mining and pointed out that the increase in abutment pressure has a significant impact on the stress distribution of the surrounding rock.

To solve the roadway deformation problem causing by the dynamic load in the Yineng coal mine, the failure characteristics of the roadway under disturbance load are studied. By establishing the disturbance model, the influence of the disturbance load on the roadway deformation and failure law is studied. Based on the failure characteristics of the roadway under disturbance, a combined support scheme is proposed. Finally, the effectiveness of the optimization scheme is verified by numerical simulation and field test.

\section{Geological Conditions}

2.1. Engineering Situation. The ground elevation of 13 belt roadway in Yineng coal mine is $+43 \sim 47 \mathrm{~m}$, and the underground elevation is $-708.4 \sim 768.5 \mathrm{~m}$. The \#3 coal seam is mainly mined, with a buried depth of $725 \sim 803 \mathrm{~m}$ and an average coal thickness of $4.0 \mathrm{~m}$. The overall structure of \#3 coal seam is an inclined syncline structure with a dip angle of $3^{\circ}$ to $17^{\circ}$. The \#3 coal is black, brown stripe, glass luster, banded structure, mainly bright coal, followed by dark coal, vitrinite, and a small amount of silk charcoal. The roof rock of \#3 coal seam is medium sandstone with a thickness of $4.3 \mathrm{~m}$, and the floor rock is mudstone with a thickness of $0.62 \mathrm{~m}$. The specific comprehensive histogram of the coal roof and the floor is shown in Figure 1.

2.2. Analysis of Original Support Plan. The 13 belt roadway is designed as a rectangular section, and its section size is $4000 \mathrm{~mm} \times 3100 \mathrm{~mm}$. The impact tendency is identified as a weak impact, and coal dust has an explosion hazard, with an explosion index of $35.94 \%$. The detailed support parameters are described below. Five $\varphi 18 \times 2200 \mathrm{~mm}$ and four $\varphi 18 \times 2200 \mathrm{~mm}$ thread steel bolts are used to support the roof and each sidewall. The row and line space of the roof and sidewall bolts are both determined to be $800 \times 800 \mathrm{~mm}$; two $\varphi 17.8 \times 6000 \mathrm{~mm}$ steel cables are used to strengthen the roof support with a distance between the cable and roof midline of $900 \mathrm{~mm}$. The specific section of the original support scheme is shown in Figure 2.

Due to the high-stress environment in the depth of the coal seam, there are obvious differences between the rock mass mechanics characteristics under the geological condition and the rock mass mechanics characteristics in the shallow depth. In shallow mining, the failure mechanism of rock is mainly brittle mechanical behavior, and the scope of plastic deformation is not large. In deep mining, there are a series of problems such as high stress, strong disturbance, and complex mining conditions (such as a larger dip angle). The disturbance load in this paper is mainly the effect of roof fracture. The failure mechanism of rock under dynamic load is mainly manifested as ductile mechanical behavior, which is often manifested as the brittle and ductile transformation of rock and zonal rupture of the surrounding rock and so on. The deformation of the surrounding rock is serious and difficult to control.

According to the field investigation of Yineng coal mine, the surrounding rock of the roadway under the original support scheme has not been effectively controlled. The analysis shows that the deformation and failure characteristics are mainly as follows. 


\begin{tabular}{|c|c|c|c|}
\hline Lithology & Formation & $\begin{array}{l}\text { Thickness } \\
(\mathrm{m})\end{array}$ & Lithology description \\
\hline \multirow{5}{*}{ 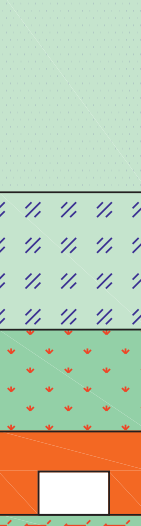 } & $\begin{array}{l}\text { Medium } \\
\text { sandstone }\end{array}$ & 11.2 & $\begin{array}{l}\text { Pale gray, oblique bedding, parallel bedding, mainly } \\
\text { quartz, feldspar, poor sorting, high hardness }\end{array}$ \\
\hline & Packsand & 6.80 & $\begin{array}{l}\text { Pale gray, wavy bedding, oblique bedding, mainly } \\
\text { quartz, feldspar, local contain a small amount of } \\
\text { siltstone lens, poor separation }\end{array}$ \\
\hline & $\begin{array}{l}\text { Medium } \\
\text { sandstone }\end{array}$ & 4.30 & $\begin{array}{l}\text { Pale gray, parallel bedding, oblique bedding, } \\
\text { mainly quartz, feldspar, round-subroundish, poor } \\
\text { sorting, high hardness }\end{array}$ \\
\hline & Coal \#3 & 4.0 & $\begin{array}{c}\text { Black, brown stripes, glassy luster, banded } \\
\text { structure, endogenous fissures developed, filled } \\
\text { with pyrite, mainly bright coal }\end{array}$ \\
\hline & Mudstone & 0.62 & $\begin{array}{l}\text { Gray-black, lumpy, uniform, medium } \\
\text { hardness, rich in fossilized plant roots }\end{array}$ \\
\hline & Siltstone & 3.80 & $\begin{array}{l}\text { Light grayish black, wavy bedding, oblique } \\
\text { bedding, lower fine interbedding, high hardness }\end{array}$ \\
\hline 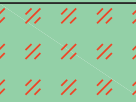 & Packsand & 5.40 & $\begin{array}{l}\text { Off-white, wavy bedding, oblique bedding, } \\
\text { quartz-based, secondary feldspar }\end{array}$ \\
\hline
\end{tabular}

FIgURE 1: Rock strata and geological description.

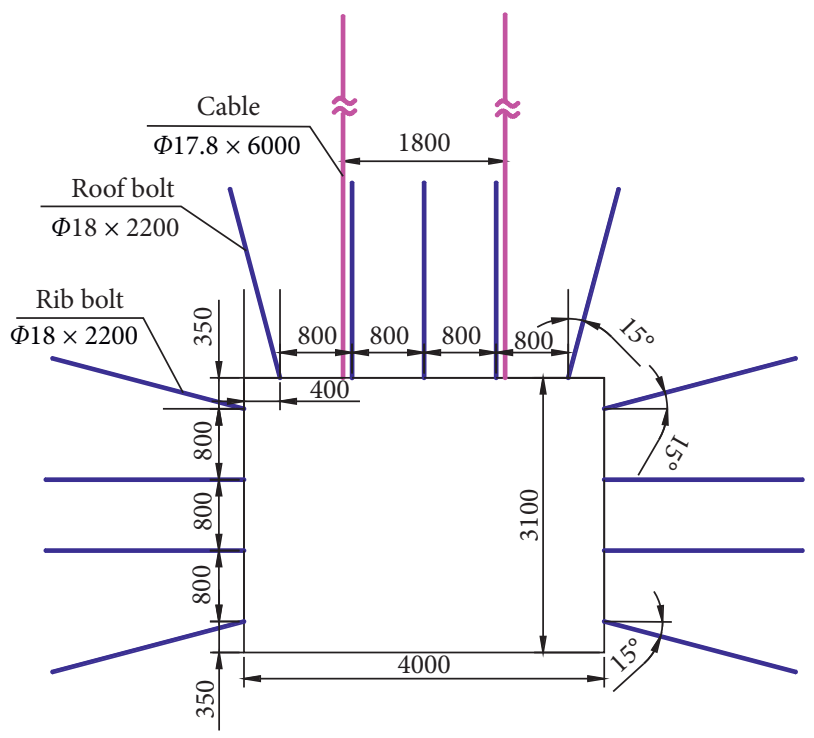

FIGURE 2: Section of the original support plan (unit: $\mathrm{mm}$ ).

2.2.1. The Two Sides of the Roadway Are Seriously Deformed. The deformation of both sides of the roadway is the main deformation and failure feature of the 13 belt roadway. The roof is a relatively hard sandstone, and both sides of the roadway are soft coal seams. The roadway floor is mudstone and siltstone, and the rock strength is relatively high, resulting in a "hard-soft-hard" sandwich structure of 13 belt roadway, which is easy to cause deformation and damage of the middle coal seam. The two sides of the roadway bear high pressure and the horizontal stress on the coal walls of the two sides of the roadway are greater than the internal friction between the two sides and the roof, which resulted in serious roadway deformation and displacement occurred at the side of the roadway. In some serious sections, the two sides of the roadway moved inward from the shoulder to the bottom, and the maximum total displacement was about $1 \mathrm{~m}$.

2.2.2. The Deformation of Both Sides of the Roof Is Serious. The failure and deformation of the roadway roof mainly occurred at the shoulders of the two sides. With the excavation of the roadway, the stress of roof and floor is released, stress concentration often occurs at four corners of the rectangular roadway, the bolt on the shoulder is squeezed, the bending and shearing phenomenon occurs, and the steel ladder shows serious distortion.

2.2.3. The Number of Support Structure Failures Is Large. The designed supporting strength of the anchor bolt and cable is low, and the shallow rock layer is soft and broken. The bolt fails to apply the preload effectively and reaches the stable inner rock layer, which leads to the bending and breaking of the bolt and the shearing and detachment of the tray from the rod body. Besides, the phenomenon of the tray cutting off the steel ladder also occurs, resulting in the loss of the function of the steel ladder.

\section{Analysis of Deformation and Failure of the Surrounding Rock}

3.1. Analysis of Mechanical Experiment. To obtain the physical and mechanical parameters of the surrounding rocks on the roof and floor of the 13 belt roadway, coal rocks such as middle sandstone, fine sandstone, floor mudstone, siltstone, and coal sample were drilled and cored in the laboratory. The corresponding data were obtained through each experiment and screened and analyzed, and the mechanical parameters test results of each coal and rock specimen were sorted out as shown in Table 1. 
TABLe 1: Physical and mechanical parameters of rock specimens from the Yineng coal mine.

\begin{tabular}{|c|c|c|c|c|c|c|c|}
\hline Lithology & $\begin{array}{l}\text { Compressive } \\
\text { strength }(\mathrm{MPa})\end{array}$ & $\begin{array}{c}\text { Tensile } \\
\text { strength } \\
(\mathrm{MPa})\end{array}$ & $\begin{array}{c}\text { Elastic } \\
\text { modulus } \\
(\mathrm{GPa})\end{array}$ & Poisson's ratio & $\begin{array}{l}\text { Density } \\
\left(\mathrm{g} / \mathrm{cm}^{3}\right)\end{array}$ & Cohesion (MPa) & Internal friction $\left({ }^{\circ}\right)$ \\
\hline Packsand & 34.3 & 4.37 & 8.21 & 0.17 & 2.72 & 3.56 & 30 \\
\hline $\begin{array}{l}\text { Medium } \\
\text { sandstone }\end{array}$ & 26.5 & 3.31 & 6.37 & 0.1 & 2.69 & 3.65 & 30 \\
\hline Coal & 7.25 & 0.79 & 0.6 & 0.24 & 1.35 & 0.84 & 42 \\
\hline Mudstone & 12.5 & 1.62 & 3.14 & 0.21 & 2.45 & 1.81 & 32 \\
\hline Siltstone & 30.6 & 3.76 & 7.32 & 0.19 & 2.71 & 2.71 & 32 \\
\hline
\end{tabular}

It can be seen from Table 1 that the tensile and compressive strength of coal seam and mudstone are low, and the average uniaxial compressive strength is $7.25 \mathrm{MPa}$ and $12.5 \mathrm{MPa}$, respectively. For the inclined coal roadway, due to the existence of coal seam inclination angle, it is easy to cause shear deformation due to the tendency of automatic sliding along the inclined plane. When the bolt dynamometer was installed at the end of the original bolt, it was found that the stress decreased when the preload was applied to a certain range. The main reason for bolt failure is that the internal surrounding rock is weak and broken, and the high prestressed bolt cannot be installed within the range of stable rock mass.

\subsection{Influence of Dynamic Load Propagation Distance.} Due to the working face advancing, roof fracture, and other disturbances, the original fractured surrounding rock around the 13 belt roadway continues to be broken under high in situ stress. After multiple disturbances, the plastic zone of the surrounding rock is larger and the deformation of the surrounding rock is more serious.

Disturbance load is usually transmitted to the roadway in the form of a stress wave. After the stress wave is generated by a dynamic load source, the amplitude becomes smaller and smaller with the time passing. It is transmitted to the plastic area, then to the fracture area, and finally to the roadway surface, resulting in the deformation of the surrounding rock. In this process, the damage caused by the disturbance stress to the surrounding rock of the roadway decreases in the direction far away from the roadway wall.

Take the disturbed load generated by artificial blasting as an example. The disturbed load is usually transmitted to the surface of the roadway in the form of a stress wave [30]. The relationship between the shape of the stress wave and the propagation distance is shown in Figure 3. With the change of the distance between the disturbance source and the roadway surface, the stress decreases gradually. When the distance from the dynamic load source is less than $15 \mathrm{R}$ ( $\mathrm{R}$ is the radius of the dynamic load source), the stress wave has a steep shape and large vibration frequency, which has a strong effect on rock failure. With the increase in the propagation distance, the waveform becomes slow within the range of $400 \mathrm{R}$ from the dynamic load source. At this time, radial cracks and annular cracks will occur in the rock [31]. At the same time, this part of the region will store a part of elastic deformation energy, which will cause rock failure when released. When the distance from the dynamic load source is more than $400 \mathrm{R}$, the amplitude of the stress wave becomes smaller. At this time, partial

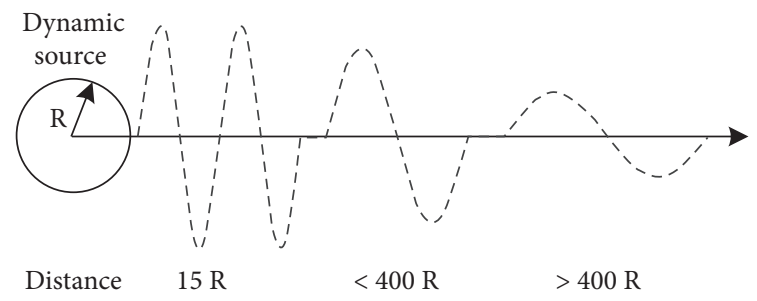

Figure 3: Dynamic load propagation process.

residual stress exists and the rock damage degree is the minimum. The magnitude of the stress wave is inversely proportional to the propagation distance.

3.3. Disturbance Region Division. The deformation of the surrounding rock of roadway can be divided into three categories: (1) the buried depth of the roadway is large, which has a great influence on roadway deformation; (2) the strength of the surrounding rock itself is low, such as some soft rock roadways, and the coal seam is weak and easy to be broken, resulting in serious deformation of the roadway; (3) the impact of dynamic load on roadway deformation, such as mining influence, ground pressure impact, and explosion load.

According to the influence of excavation disturbance on the Yineng coal mine, the failure scope of surrounding rock is divided into three areas. The first area is the weak and broken area. Due to excavation disturbance, the original surrounding rock stress is shifted and concentrated. When the concentrated stress exceeds the strength of the rock, the soft and broken structure formed on the surface of the roadway leads to the yield failure of the rock mass. With the influence of disturbing load, the shallow part of the surrounding rock of the roadway firstly produces large fractures and deformation. The role of bolt support firstly restrains the damage and deformation of the roadway surface, and secondly, it goes deep into the stable rock layer to participate in the common bearing of the surrounding rock. The second area is the weak stress concentration area. Because of the transfer and release of stress in the first region, a concentrated radial compression effect is generated in this region, which causes greater plastic deformation and cracks in this region, resulting in lower bearing capacity of the surrounding rock. The deformation of the third area is smaller than that of the first two areas, which is mainly represented by elastic deformation. The stress becomes very weak after reaching this area. The remaining stress is absorbed by the 
deep stable rock mass and gradually returns to the original rock stress state.

Therefore, the key to maintaining the stability of the roadway is to ensure the stability of the surrounding rock in the first two areas. Bolts and shotcrete can turn the first weak fracture zone into an effective whole. Bolt support has very good self-stability and flexibility characteristics, which can realize active support. At the same time, due to the radial support force of the bolt, the original broken surrounding rock can be compacted, thus forming a more stable extrusion bearing layer [32, 33].

\section{Numerical Simulation of Dynamic Load}

The built-in power module in FLAC3D can be used to build the model and directly input the dynamic load. By analyzing the strength and frequency of different disturbance loads, the influence of different dynamic load forms on roadway deformation is simulated. The changes in stress distribution, displacement, and plastic zone before and after dynamic load were recorded.

4.1. Dynamic Parameter Setting. When the numerical simulation software is used for dynamic calculation, the setting of boundary conditions and the selection of disturbance load should be carried out first. According to the elastic wave theory, any form of the dynamic load will be transmitted outward in the form of a stress wave. Therefore, FLAC3D software reduces the reflection of the wave on the model boundary by setting the damping coefficient [34]. Since the viscous force provided by the damper cannot be applied directly on the static boundary, the velocity-time history should be converted to the stress time history and applied on the boundary when the dynamic load is to be applied on the static boundary. The conversion formula is as follows:

$$
\begin{gathered}
\delta_{n}=-2\left(\rho C_{p}\right) v_{n}, \\
\delta_{s}=-2\left(\rho C_{s}\right) v_{s},
\end{gathered}
$$

where $\delta_{n}$ and $\delta_{s}$ are the normal and tangential stresses applied on the model boundary, respectively, and $C_{p}$ and $C_{s}$ are the wave velocities of compression and shear waves in the medium, respectively, and $v_{n}$ and $v_{s}$ are the normal and tangential vibration velocities on the model boundary, respectively, and $\rho$ is the medium density.

According to the relevant research, any disturbance can be converted into the form of harmonic in the numerical calculation [35]. Therefore, the first step is to analyze the form of a stress wave. A section of the harmonic wave is selected as disturbance load, and the expression is as follows:

$$
\sigma=\left\{\begin{array}{l}
0.5 \sigma_{\max }\left[1-\cos (2 \pi \omega t)\left(t<\frac{1}{\omega}\right)\right], \\
0\left(t>\frac{1}{\omega}\right),
\end{array}\right.
$$

where $\sigma_{\max }$ is the disturbance stress intensity, which can be taken as $10 \mathrm{MPa}, 20 \mathrm{MPa}, 30 \mathrm{MPa}$, and $40 \mathrm{MPa}$, respectively. In this simulation, $20 \mathrm{MPa}$ is selected as $\sigma_{\max }$, and $50 \mathrm{~Hz}$ is selected as $\omega$ (frequency of disturbance). As time goes on, the disturbing stress wave gradually decreases, and the diagram of the disturbing dynamic wave is shown in Figure 4.

4.2. Dynamic Model Establishment. According to the above analysis of boundary conditions, the flow chart of the numerical model is shown in Figure 5. The model is first to run to equilibrium to generate the in situ stress, and then excavation calculation is carried out. After the excavation results are obtained, the dynamic calculation boundary is set and dynamic load is applied for dynamic calculation. Recalculate steps (1)-(5) by changing the intensity and frequency of the disturbance load in step (3) to study the influence of the disturbance load on the failure and deformation of the roadway.

According to the relevant research, the influence of roadway excavation disturbance is $3-5$ times that of the tunnel section size. The disturbance caused by the roof fracture is also roughly within this range. Therefore, the disturbance load is applied above the model. Firstly, the overburden rock is loaded with $20 \mathrm{MPa}$. Before the dynamic calculation, the roadway is in an unsupported state. After excavation calculation, the dynamic stress wave is applied to the top of the rock for dynamic calculation. The schematic diagram of the model is shown in Figure 6.

\subsection{Influence of Disturbed Load on Roadway Deformation.} After the excavation of the roadway, the static excavation calculation is carried out first, and then the dynamic calculation is carried out by applying the disturbance load with a strength of $10 \mathrm{MPa}$ on the top of the model. The stress change, displacement, and plastic zone distribution of surrounding rock before and after disturbance are recorded, respectively. By comparing the stress distribution of two different forms, the influence of disturbed load on surrounding rock deformation is analyzed.

The distribution of shear stress in the surrounding rock before and after the dynamic load is shown in Figure 7. Before the disturbance, the stress was redistributed for the first time after the excavation of the roadway. Different degrees of shear stress concentration were formed on the roof and both sides. The maximum shear stress was $10.6 \mathrm{MPa}$ and concentrated in the range of $1.5 \mathrm{~m}$ on both sides. After the excavation, disturbed stress of $20 \mathrm{MPa}$ was applied to the top of the model for a duration of $0.1 \mathrm{~s}$. It can be seen from Figure 7(b) that the shear stress in the vertical direction moves downward and begins to concentrate in the upper part of the roof. The maximum shear stress of the two sides reaches $12.46 \mathrm{MPa}$, and the stress concentration is more obvious under the influence of disturbance load and transfers to the depth of the two sides. The maximum shear stress is concentrated in the range of $2.5 \mathrm{~m}$ on both sides of the roadway. By comparing the shear stress distribution before and after the disturbance load, it can be found that the first stress redistribution occurs immediately after the 


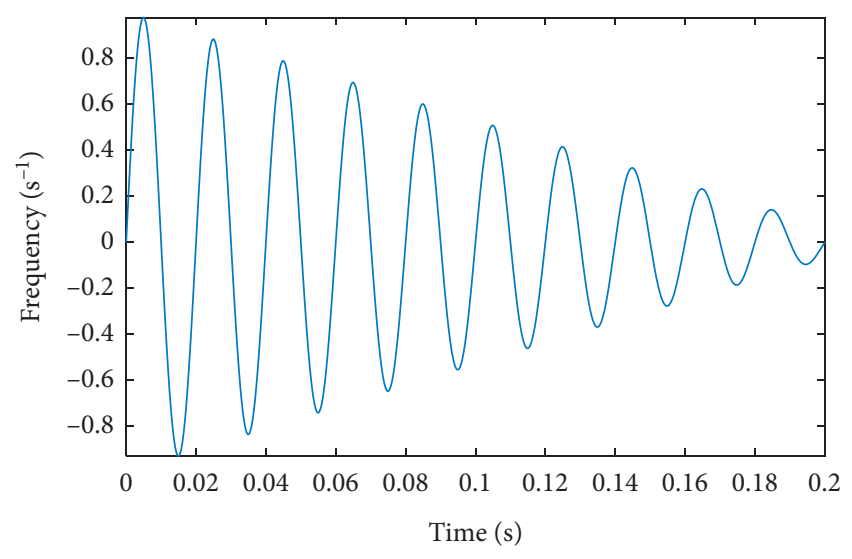

Figure 4: Schematic diagram of dynamic wave disturbance.

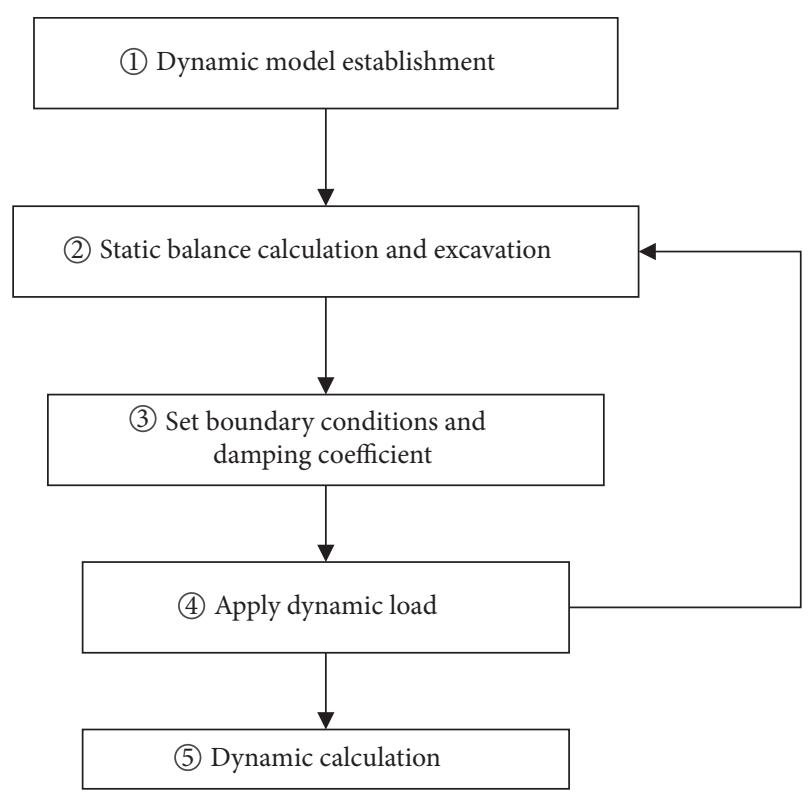

FIGURE 5: Schematic diagram of dynamic wave disturbance.

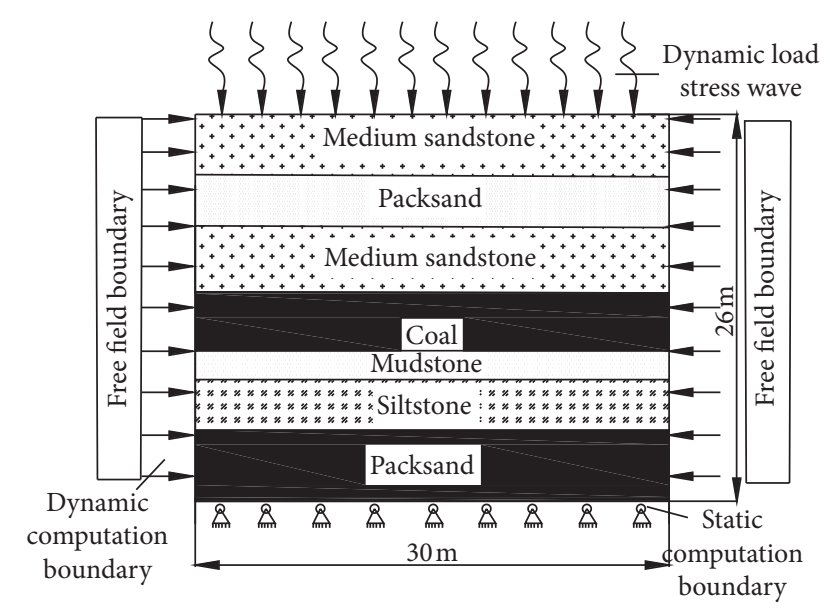

Figure 6: Model schematic diagram. excavation of the roadway. After the disturbance load is applied, the stress field of the surrounding rock is redistributed for the second time, which is more obvious than that in the static calculation, and the maximum stress concentration area is enlarged more than 2 times and transferred to the deeper part of the two sides.

The plastic zone change of surrounding rock before and after the disturbance load is shown in Figure 8. It can be seen from Figure $8(\mathrm{a})$ that the surrounding rock is rapidly destroyed under high stress after roadway excavation. The plastic zone range in the roof was larger than that on two sides and the floor. After the disturbance, large-scale failure occurred at the corner of the roadway, mainly shear failure deformation, and the plastic zone of surrounding rock tended to expand. The reason is that the plastic failure of surrounding rock has occurred under excavation, which is the relaxation area of surrounding rock. Under the action of disturbance load, the propagation of stress wave makes surrounding rock more broken, and the loose range expands inward which deepens the damage degree of surrounding rock [36].

The vertical displacement change of surrounding rock before and after the disturbance load is shown in Figure 9. After the disturbance load is applied, the maximum vertical displacement of roof settlement reaches $75.9 \mathrm{~mm}$, which is 1.86 times larger than that under static excavation. It can be seen from Figure 9(b) that the displacement of the upper part of the roof tends to gradually sink, and the maximum displacement position is gradually transferred from the top of the model to the roadway roof, and the floor displacement is relatively small. This is because the stress wave from the top propagates to the roof of the roadway, and the stress wave transmission is greatly reduced. Thus, the disturbance only has a large influence on the roof but a small influence on the floor. The maximum displacement position is concentrated in the range of $0 \sim 1.5 \mathrm{~m}$ of the roof.

4.4. Influence of Different Disturbance Loads on Roadway Deformation. The possible sources of dynamic load include rock fracture and collapse, fault sliding, artificial blasting, and natural earthquake. Therefore, different disturbance intensities are studied here to reproduce different dynamic load sources.

Keeping the disturbance frequency unchanged at $50 \mathrm{~Hz}$, the influence of different disturbance loads on roadway deformation is studied by changing the intensity of the disturbance load. The applied disturbance load is 0.5 times, 1 time, and 2 times of the initial static load, respectively, which are $10 \mathrm{MPa}, 20 \mathrm{MPa}$, and $30 \mathrm{MPa}$, respectively. The stress and displacement changes at different positions of the roadway roof and floor are recorded as shown in Figures 10(a) and 10(b), and the horizontal and vertical stresses at different positions of the side are recorded as shown in Figures 10(c) and 10(d).

It can be seen from Figure 10(a) that the roof subsidence increases with the increase in disturbance intensity. When the disturbance intensity is $10 \mathrm{MPa}$, the maximum displacement is $55.24 \mathrm{~mm}$, which is 1.07 times larger than 
Contour of Max. shear stress

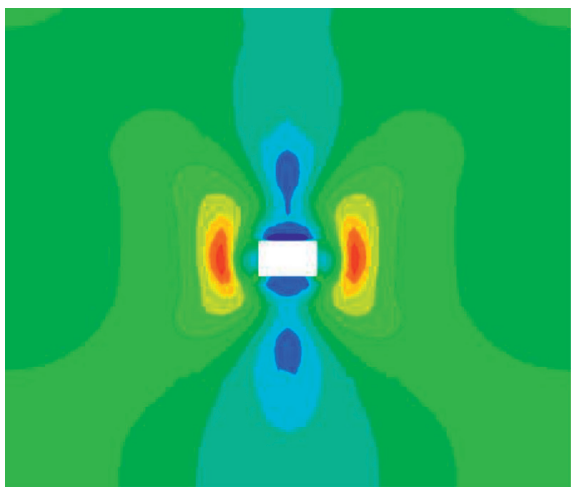

(a)

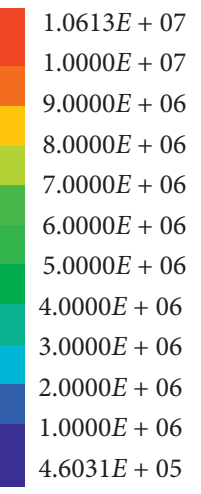

$4.6031 E+05$

FiguRE 7: Distribution diagram of surrounding rock shear stress before and after disturbance. (a) Before applying disturbance load. (b) After applying disturbance load.

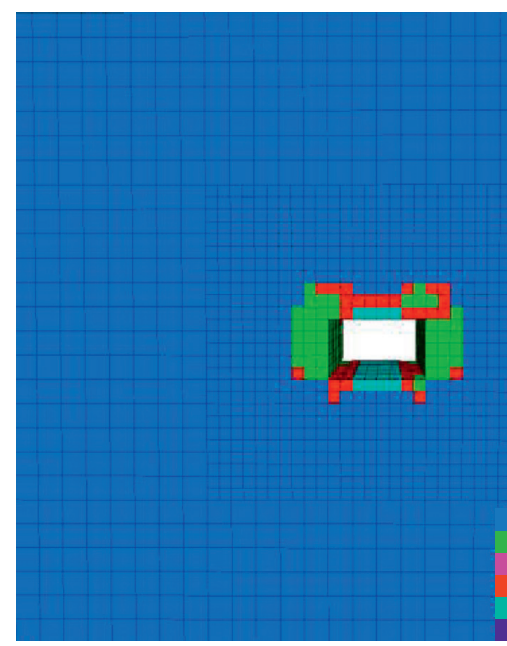

(a)

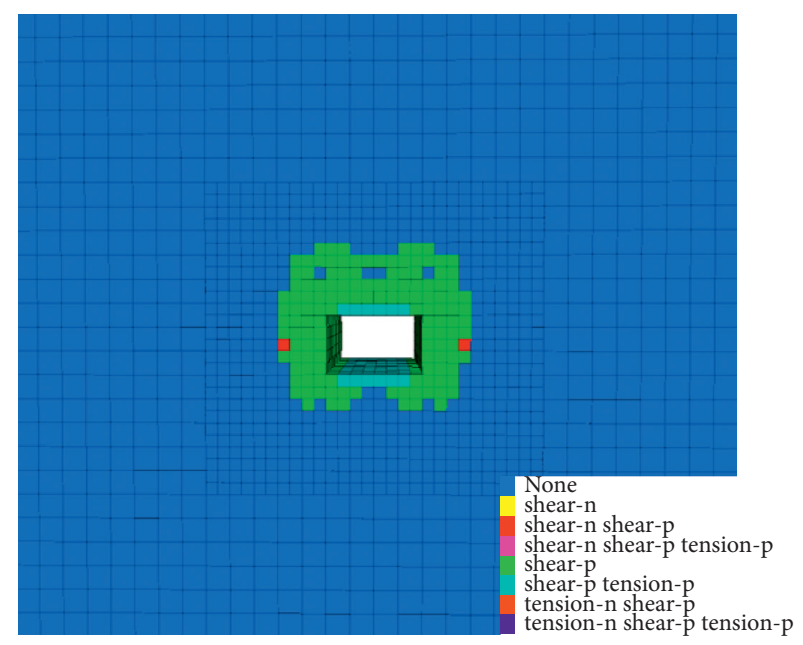

(b)

Figure 8: Distribution of the plastic zone of the surrounding rock (a) before applying disturbance load and (b) after applying disturbance load.

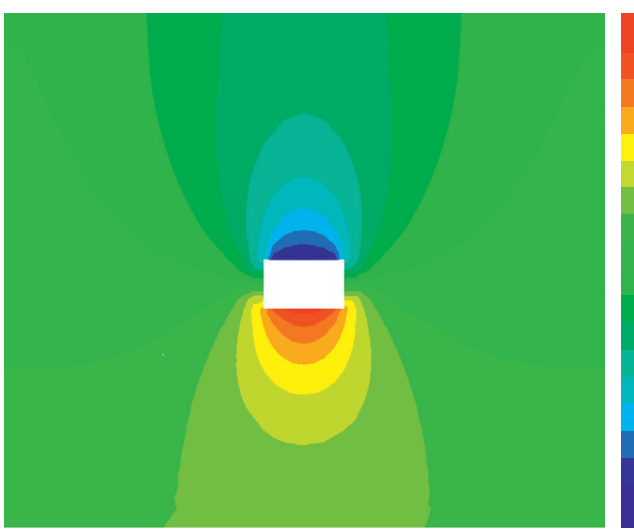

(a)
Contour of Max. shear stress

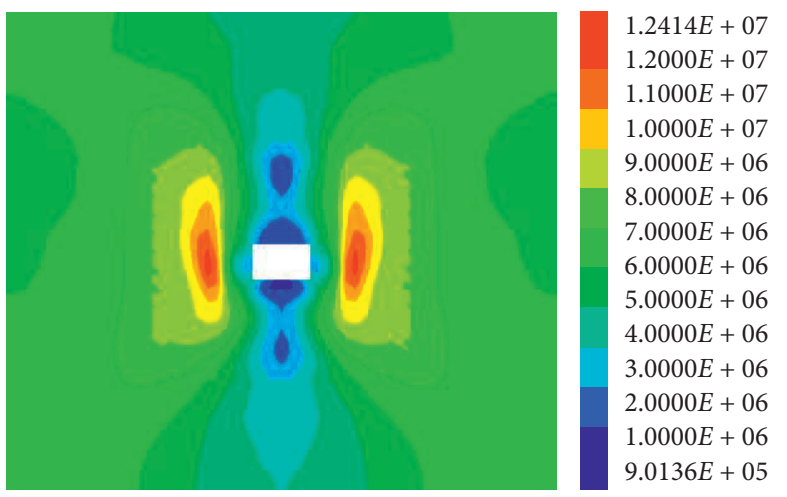

(b)
ZDISP (m)

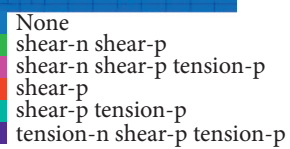

hear-p tension-p

tension-n shear-p tension-p

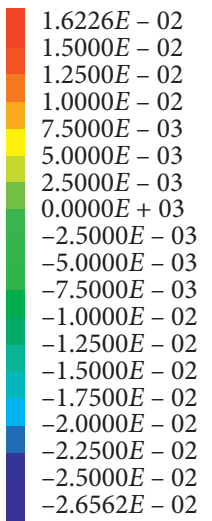

$-2.6562 E-02$
ZDISP (m)

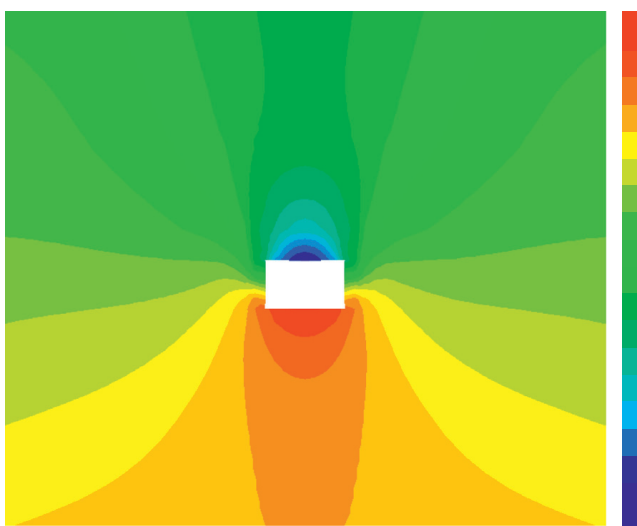

$2.0467 E-02$

$1.5000 E-02$

$5.0000 E-03$

$-5.0000 E-03$

$-1.5000 E-02$

$-2.5000 E-02$

$-3.5000 E-02$

$-4.5000 E-02$

$-5.5000 E-02$

$-6.5000 E-02$

$-7.5000 E-02$

$-7.5986 E-02$

(b)

FIGURE 9: Distribution of the plastic zone of the surrounding rock (a) before applying disturbance load and (b) after applying disturbance load. 


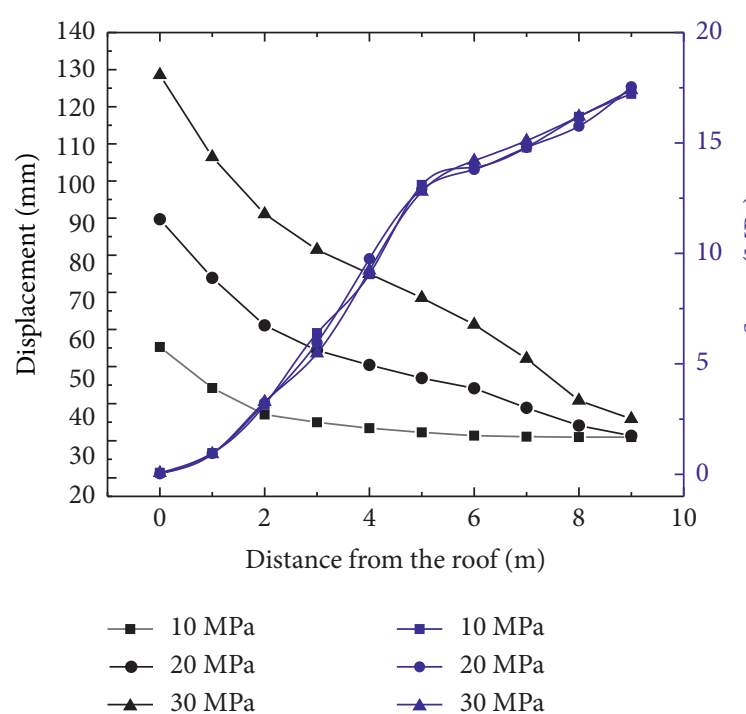

(a)

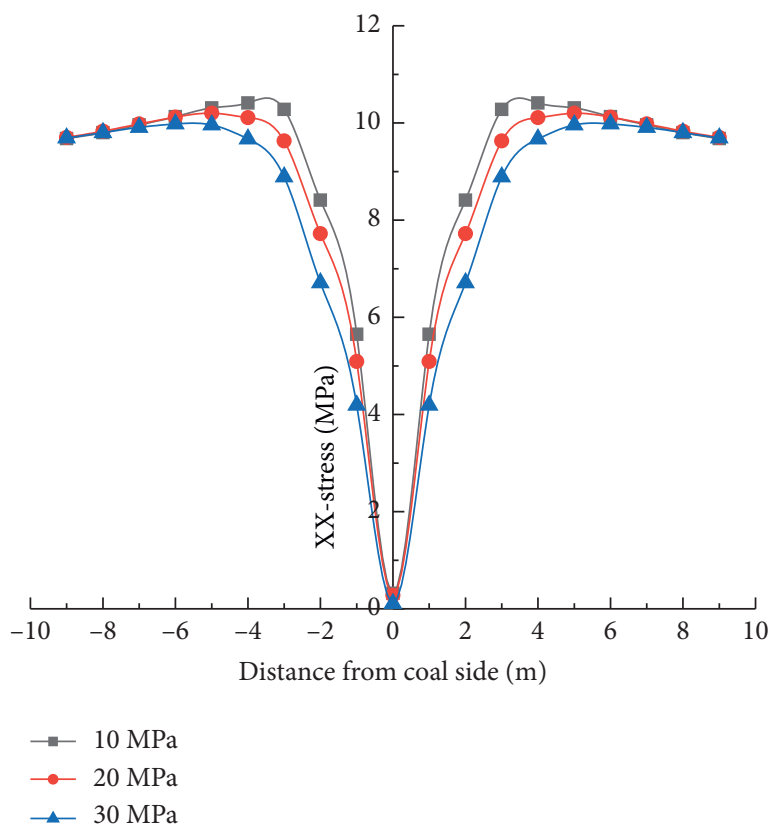

(c)

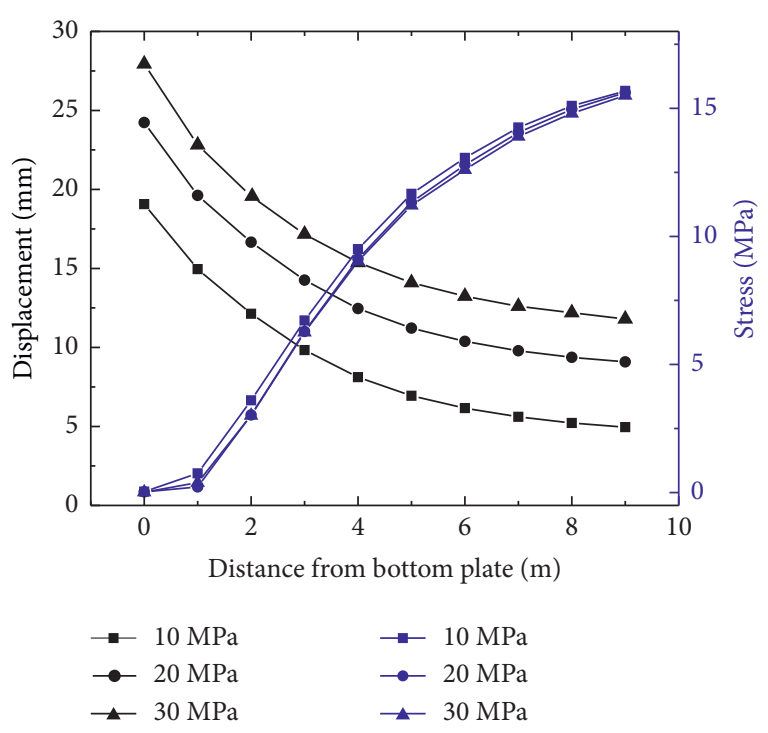

(b)

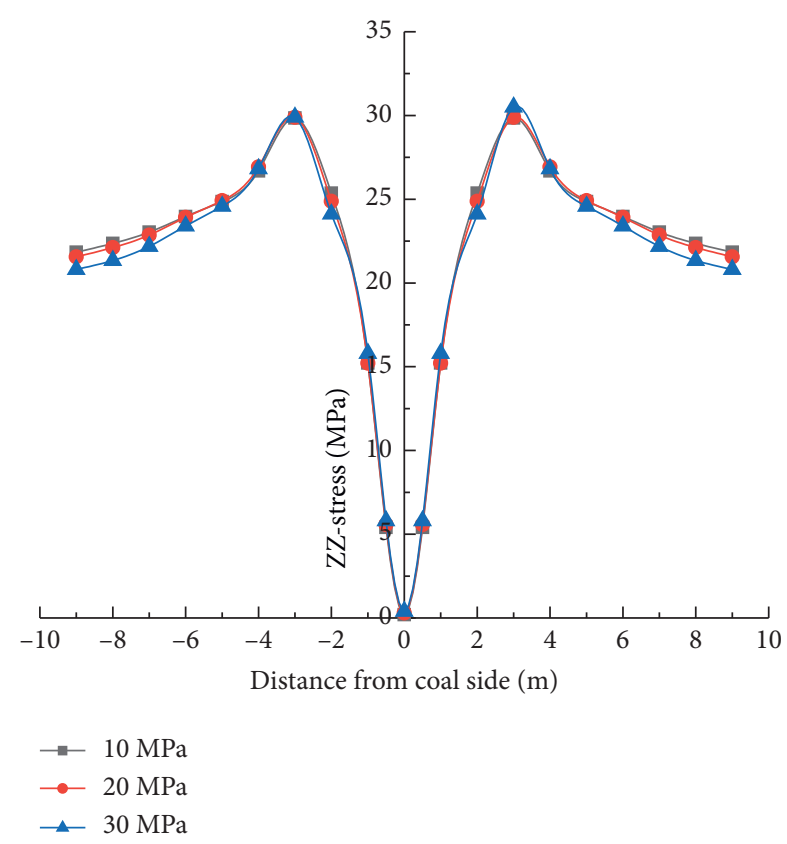

(d)

FIGURE 10: Deformation law of surrounding rock.

before. When the disturbance intensity reaches $30 \mathrm{MPa}$, the maximum displacement is $128.57 \mathrm{~mm}$. It can be seen from Figure 10(b) that with the increase in disturbance intensity, the floor heave does not change significantly, and the floor stress also changes little. The increase in disturbance intensity mainly acts on the roof and has little effect on the floor. When the stress wave of the roof is transmitted to the roof, only a small part of the stress wave acts on the floor through the two sides, while most of the disturbing stress acts on the roof and the two sides. When the stress wave is transmitted to the floor, the attenuation of the stress wave is obvious and the disturbance to the floor is small. As shown in Figures 10(c) and 10(d), with the increase in disturbance intensity, the vertical stress increases more than the horizontal stress. With the increase in the distance from the roadway side, both vertical and horizontal stress distributions tend to increase first, then decrease, and finally become stable, and the whole stress distribution features show an "M" trend. The maximum stress in both horizontal and vertical directions is concentrated in the range of $2 \sim 4 \mathrm{~m}$.

4.5. Influence of Different Disturbance Frequencies on Roadway Deformation. In underground mining operations, the stress waves generated by different dynamic load sources are varied. After the dynamic load source generates the stress wave, the action time is relatively short, and the stress wave waveform obtained by field monitoring is very complicated. 

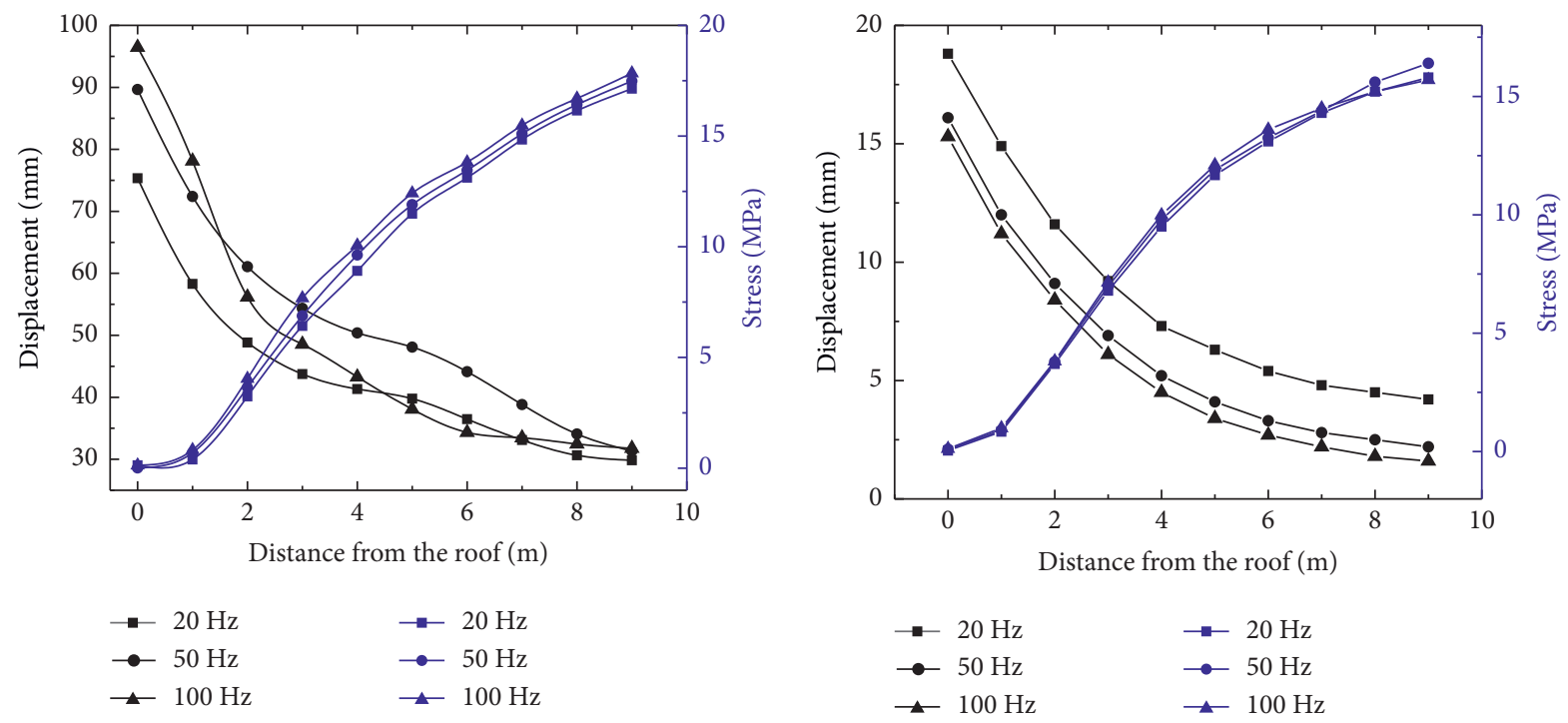

(a)

(b)
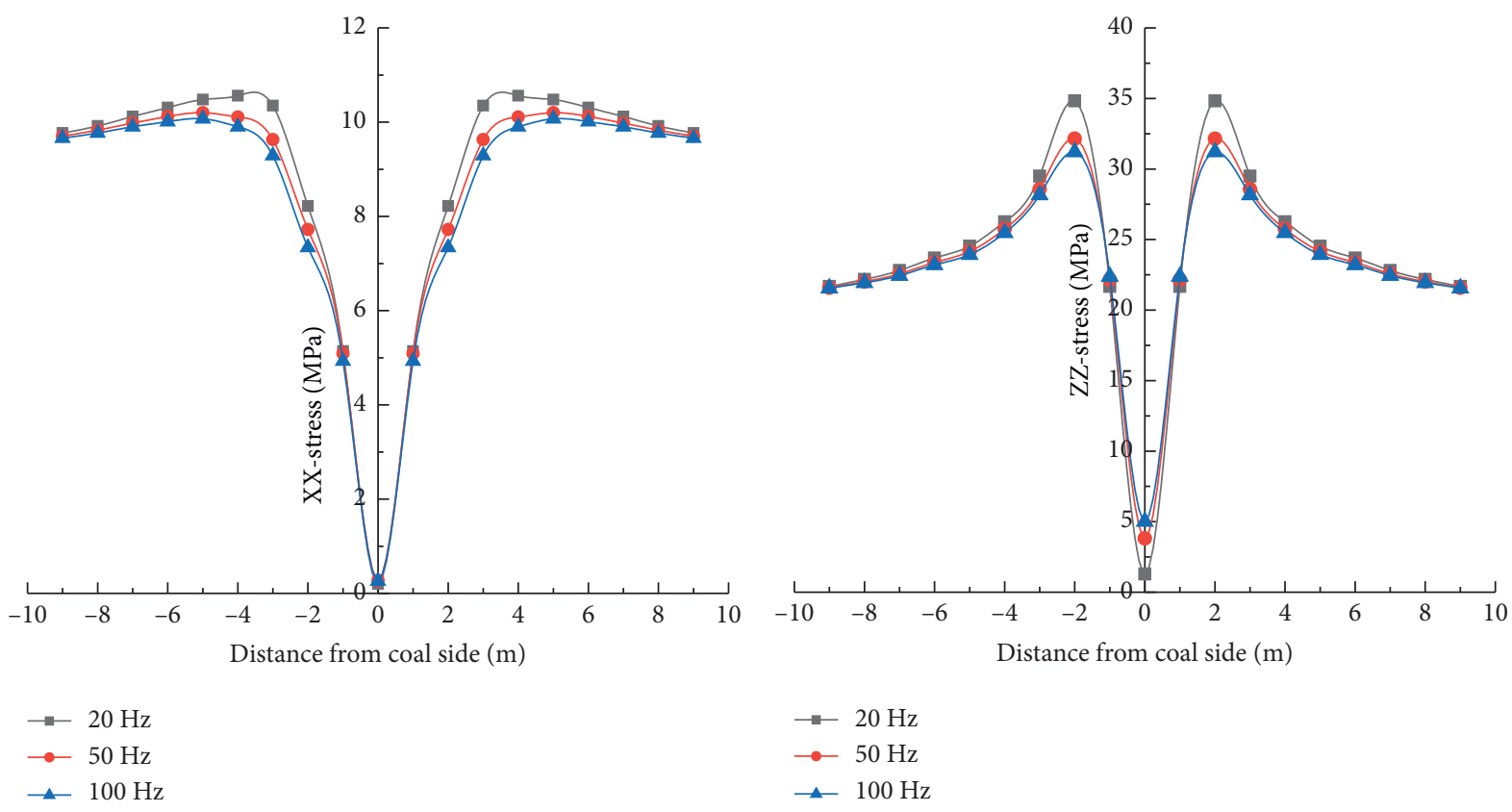

(c)

(d)

FIGURE 11: Deformation law of surrounding rock under different disturbance frequencies.

By setting different frequency waveforms, numerical simulation can be used to study the dynamic load generated by different dynamic load sources such as face mining, roof fracture, and artificial blasting. Keeping the disturbance intensity unchanged at $20 \mathrm{MPa}$, different waveform functions were set to study the influence of different disturbance frequencies on the roadway deformation. Take the disturbance frequency of $20 \mathrm{~Hz}, 50 \mathrm{~Hz}$, and $100 \mathrm{~Hz}$ as examples, the roof and floor displacement and stress change curve diagram of the numerical roadway is shown in Figure 11.

Both roof subsidence and floor heave increase with the increase in disturbance frequency, and the change rate of roof subsidence gradually accelerates. The result shows that the disturbance load frequency has relatively little influence on the change rate of the floor. The stress variation between roof and floor is not obvious, and the stress is smaller when it is close to the roof and floor of the roadway. With the distance from the roof and floor, the stress increases gradually and the displacement changes very little. As the disturbance range of roadway excavation is usually $3-5$ times the radius of the roadway, the surrounding rock far from the roadway stays stable while the stress is close to the in situ stress. It can be seen from Figures 11(c) and 11(d) that with the increase in disturbance frequency, the impact of the dynamic load causes more serious deformation. The stress in the shallow surrounding rock is released due to the fracture 
and deformation of the rock mass, and the horizontal stress is reduced. The stress in the deep stable surrounding rock gradually approaches the in situ stress. The overall stress change shows a trend of decreased first and then increased and then decreased. The stress is concentrated in the position of $2 \sim 3 \mathrm{~m}$ on the side from the surface, which is also the vague range of the loose zone of surrounding rock.

\section{Support Optimization and Effect Verification}

Borehole detection was carried out for the on site observation of Yineng coal mine. According to the detection result, the maximum fracture range of the two sides is about $2.0 \mathrm{~m}$. Meanwhile, the effect of the original support scheme is not obvious which is difficult to maintain the stability of the roadway. With the increase in disturbance, the roof subsidence is larger while the roof collapses occurred during field observation, and the two sides move inward which indicates that the surrounding rock is broken. Based on the above research, the theory of squeeze bearing arch is adopted in this research. As shown in Figure 12, $r_{0}$ is the radius of the roadway, $R_{0}$ is the radius of the loosening circle, and $R$ is the radius of the plastic zone. According to the squeeze bearing arch theory, when multiple anchor cables are installed at the same time, the compressive stress regions are combined to form a new and stronger compressive stress structure. The bearing area formed by the anchor rod is within the range of the loosening circle, so it is considered to add the anchor cable at the side. By adjusting the spacing and length of anchor cables, the two bearing layers can be superimposed on each other to form a more stable bearing layer. As shown in Figure 13, a shallow bearing layer is formed between the bolts, and a deeper bearing layer is formed between the bolts and the anchor cables, and a more stable bearing structure is formed by the mutual extrusion between the bearing layers. The roadway surface is supported by shotcrete with anchor mesh, and the inner displacement of the side is controlled by the anchor cable in two sides. The secondary support should be confirmed in a serious section to confirm that the support can effectively control the damage and deformation of the roadway caused by a disturbance in time.

5.1. Optimized Support Scheme. Based on the deformation characteristics of the roof and two sides of the 13 belt roadway, the optimization support scheme shown in Figure 14 is proposed.

5.1.1. Roof Support. Six $\varphi 18 \times 2200 \mathrm{~mm}$ high strength bolts are used to support the roof. The yield strength is greater than $500 \mathrm{MPa}$, and the spacing between rows is $750 \mathrm{~mm} \times 800 \mathrm{~mm}$. The specification of the anchor rod tray is $150 \mathrm{~mm} \times 150 \mathrm{~mm} \times 10 \mathrm{~mm}$. M22 damping nut, wearreducing washer, and ball washer are used together with one pressure tube. Two K2545 resin anchorage agents are used for the end anchor of each bolt, and the pretightening force is not less than $80 \mathrm{kN}$.

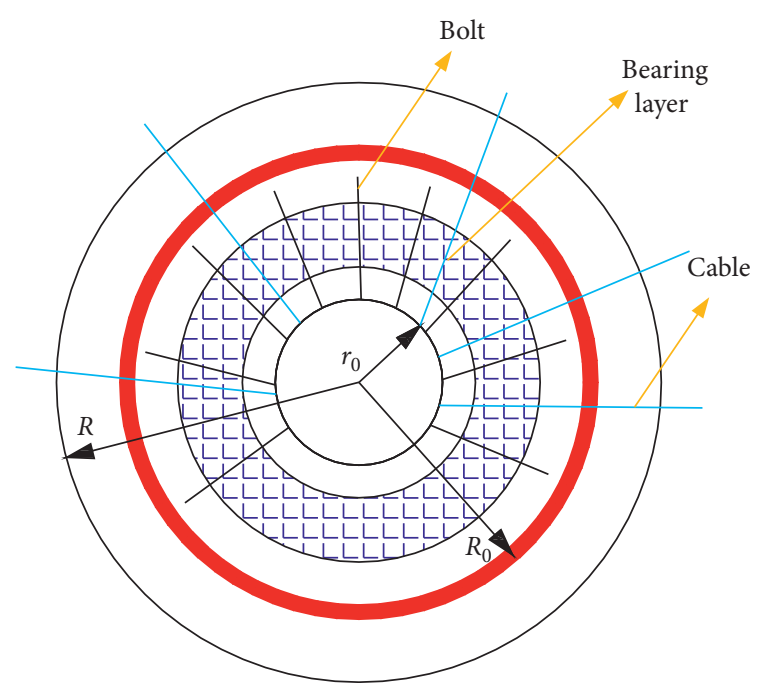

FIGURE 12: Relationship between loose ring and support position.

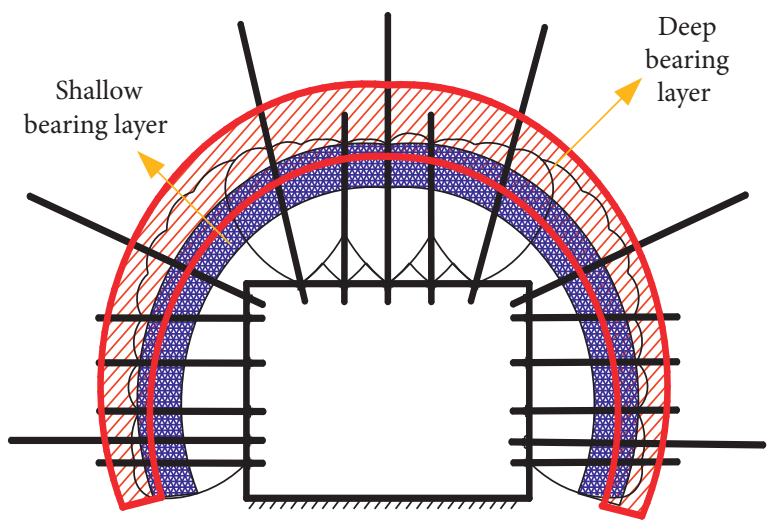

FIgURE 13: Schematic diagram of bearing layer.

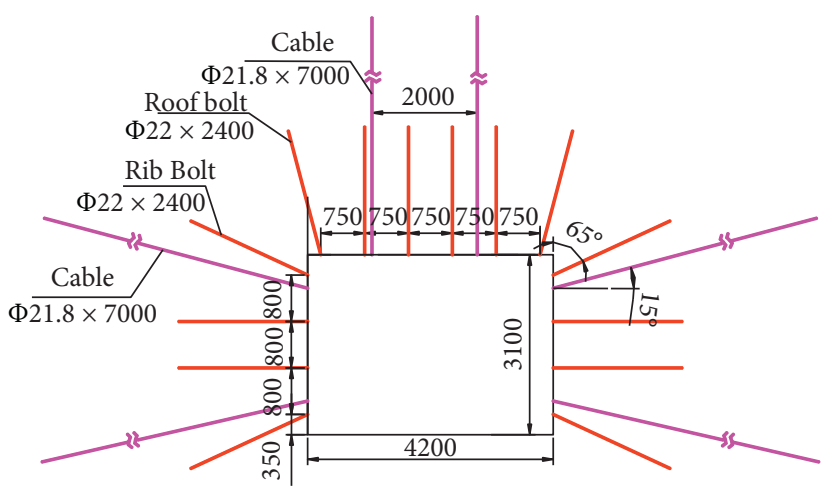

FIGURE 14: Schematic diagram of optimization scheme (unit: mm).

5.1.2. Sides Support. Five $\varphi 22 \mathrm{~mm} \times 2400 \mathrm{~mm}$ high strength bolts are used to support each side of the roadway. For the position of the large deformation, add two $\varphi 21.8 \mathrm{~mm} \times 7000 \mathrm{~mm}$ anchor cables with a pretightening force of $240 \mathrm{kN}$, and the row spacing is $2000 \mathrm{~mm} \times 2400 \mathrm{~mm}$. 


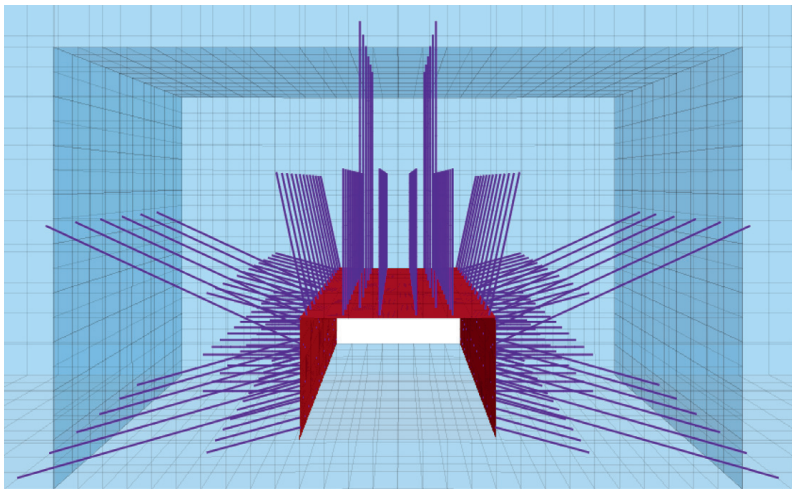

FIgURE 15: Simulation schematic diagram.
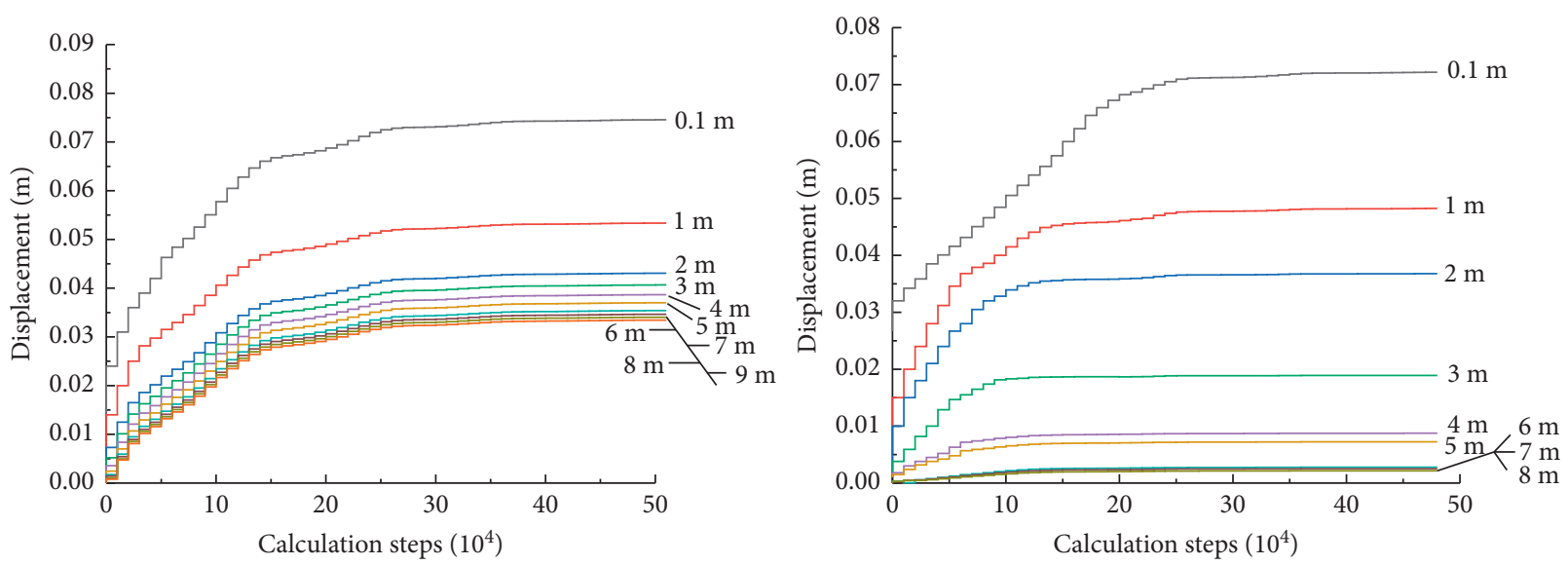

FIGURE 16: Simulated displacement evolution of the supported roadway.

The anchor cable tray is selected as $300 \mathrm{~mm} \times 300 \mathrm{~mm} \times 20 \mathrm{~mm}$. Two pressure tubes are used for the anchor cable, and each cable is anchored with 3 K2545 resin anchorage agents.

5.1.3. Strengthen Support. The two sides of the roadway are laid with $50 \mathrm{~mm} \times 50 \mathrm{~mm}$ latitude and longitude metal mesh which is made of 12 \# galvanized iron wire, the mesh is butted, and a buckle is connected every $200 \mathrm{~mm}$ to ensure that the mesh is not torn. At the same time, the $\mathrm{W}$-shaped steel belt of WD280/3.0 with a length of $4.2 \mathrm{~m}$ is selected.

5.2. Numerical Simulation Verification. The FLAC3D numerical simulation software is used to simulate the changes of the roadway roof and ledge displacement with the optimized support scheme, as shown in Figure 15. The displacement changes of the roadway roof within 0-9 $\mathrm{m}$ and the right side within $0-8 \mathrm{~m}$ are recorded, respectively, as shown in Figure 16. It can be seen from the results that the surrounding rock deformation eventually stabilizes, and the maximum deformation of the roof is only $72.21 \mathrm{~mm}$. The roadway surface displacement change is smaller as the surface distance is farther, and the displacement change is little at the position of 6-8 $\mathrm{m}$ away from the roadway surface. The simulation results show that the optimized support scheme can effectively control the damage and deformation of the roadway.

5.3. Field Application. To verify the deformation of the roadway under the new support method, a typical section of the roadway of the 13 belt roadway is selected to monitor the deformation of the roadway surrounding rock. According to the displacement monitoring curve shown in Figures 17 and 18, the monitoring results after adopting the optimized support scheme on the $30^{\text {th }}$ day are as follows: roof subsidence is $126 \mathrm{~mm}$, floor heave is $33 \mathrm{~mm}$, and the total displacement of roof and floor is $159 \mathrm{~mm}$. The displacement of the left side was $116 \mathrm{~mm}$, and that of the right side was $132 \mathrm{~mm}$. The total displacement of the two sides was $248 \mathrm{~mm}$. Roof subsidence increases rapidly within 15 days after roadway tunneling and increases very slowly after the $18^{\text {th }}$ day, which finally tends to be stable. Floor heave increased rapidly in 9 days after roadway tunneling, but after the $12^{\text {th }}$ day, the growth rate was extremely slow and stabilized. The moving quantity of the two sides increased rapidly in 15 days after roadway tunneling and increased 


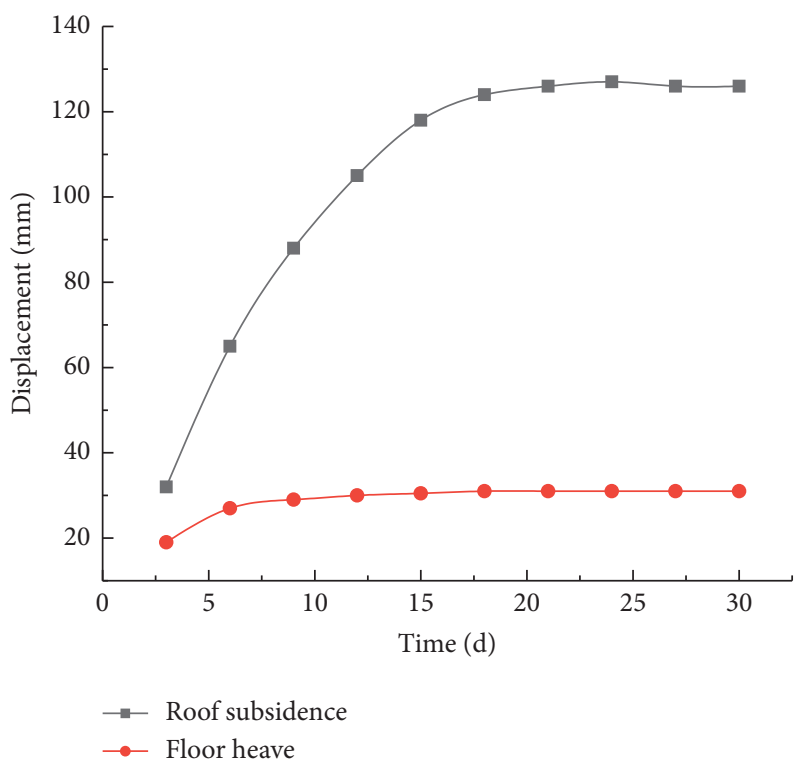

FIgURE 17: Amount of roof sinking and floor heave.

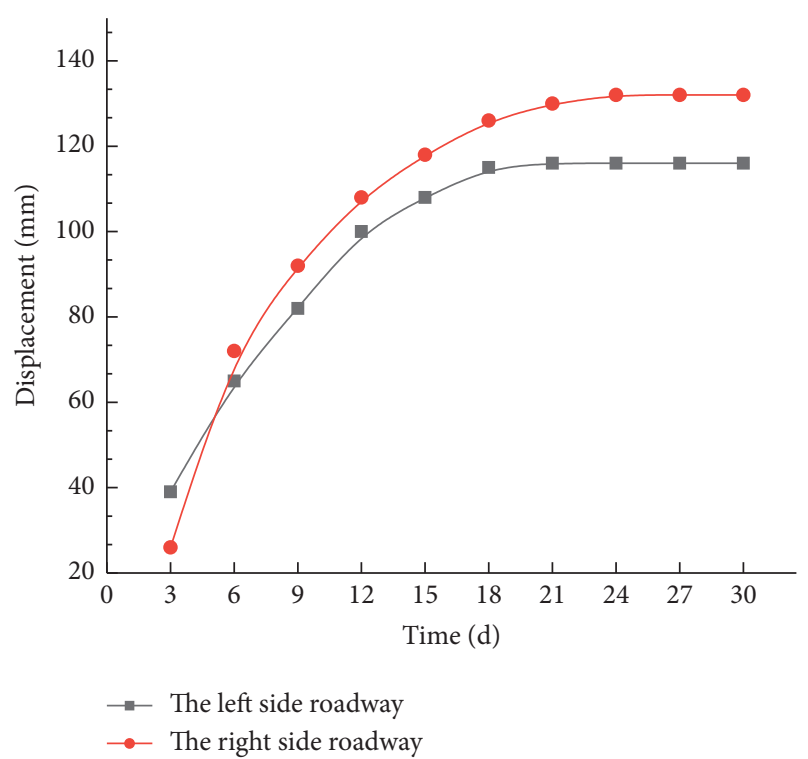

Figure 18: The displacement of the two sides.

very slowly after 21 days. The monitoring data are consistent with the simulation results. Therefore, roadway deformation has been effectively controlled. The new support scheme makes the original broken areas form a stable whole together, and the superimposed bearing layer structure formed by the joint action of anchor bolts and cables is strengthened.

\section{Conclusion}

(1) In this study, numerical models are used to study the stability of roadways under different dynamic loads. The influence of four different disturbance intensities on roadway failure and deformation is discussed.
Based on the theory of the surrounding rock bearing layer, the damage and deformation of the surrounding rock are divided into three layers. The main function of bolt support is to maintain the stability of the deep bearing layer.

(2) Based on the engineering background of the 13 roadway in the Yineng coal mine, the stress distribution of the roof and the two sides of the roadway under different dynamic load frequencies is analyzed. The results show that as the intensity of the disturbance load increases, the roadway deformation increases significantly due to the dynamic load. The sinking amount of the top plate and the displacement of the two sides are larger, and the bottom drum value is smaller. Under the same dynamic load strength, the greater the dynamic load frequency, the greater the increase in roadway deformation, and the roadway is more prone to deformation and instability.

(3) After the dynamic load was applied, the subsidence of the roof increased by 1.86 times, and the plastic zone expanded significantly. With the increase in disturbance intensity and frequency, the maximum roof subsidence increases by 2.33 times. According to the deformation of roadway surrounding rock, a combined support scheme of "two reinforced anchor cables + steel mesh $+W$ steel belt" is proposed. The dynamic load causes impact damage to the roadway. This scheme can effectively improve the bearing capacity between the support and the surrounding rock and at the same time enhances the support strength of the surrounding rock.

(4) The new optimal support scheme is applied to the Yineng coal mine. During the monitoring period of one month, the roadway deformation tends to be stable. The final monitoring results show that the 
maximum subsidence of the roof is $126 \mathrm{~mm}$ and the total maximum displacement of the two sides is $248 \mathrm{~mm}$, which verify the rationality of the optimized support plan.

\section{Data Availability}

The data used to support the findings of this study are included within this paper.

\section{Conflicts of Interest}

The authors declare that they have no conflicts of interest.

\section{Acknowledgments}

This research was supported by the Shandong Provincial Natural Science Found (ZR2019MEE022 and ZR2020QE119) and National Natural Science Foundation of China (52004145).

\section{References}

[1] C. Zang, M. Chen, G. Zhang, K. Wang, and D. Gu, "Research on the failure process and stability control technology in a deep roadway: numerical simulation and field test," Energy Science \& Engineering, vol. 8, pp. 1-14, 2020.

[2] B. Duan, H. Xia, and X. Yang, "Impacts of bench blasting vibration on the stability of the surrounding rock masses of roadways," Tunnelling and Underground Space Technology, vol. 71, pp. 605-622, 2018.

[3] Z. Guo, J. Wang, and Y. Zhang, "Failure mechanism and supporting measures for large deformation of tertiary deep soft rock," International Journal of Mining Science and Technology, vol. 25, no. 1, pp. 121-126, 2015.

[4] G. Qi, Z. J. Li, and Z. B. Guo, "Coupling support design for deep pit bottom in No. 5 coal mine of He bi coal industry group and its application," Journal of Mining and Safety Engineering, vol. 28, no. 4, pp. 553-559, 2011.

[5] S. M. Pandit, F. O. Otuonye, and R. X. Sun, "Spectrum analysis of a mechanical bolt system under impact by using the DDS methodology," Proceedings of SPIE-Te International Society for Optical Engineering, vol. 3089, pp. 119-127, 1997.

[6] X. Li, T. Zhou, and D. Li, "Dynamic strength and fracturing behavior of single-flawed prismatic marble specimens under impact loading with a split-Hopkinson pressure bar," Rock Mechanics and Rock Engineering, vol. 50, no. 1, pp. 29-44, 2017.

[7] M. Tao, A. Ma, W. Cao, X. Li, and F. Gong, "Dynamic response of pre-stressed rock with a circular cavity subject to transient loading," International Journal of Rock Mechanics and Mining Sciences, vol. 99, pp. 1-8, 2017.

[8] S. Y. Chen, C. S. Song, Z. B. Guo, J. Wang, and Y. Wang, "Asymmetric deformation mechanical mechanism and control countermeasure for deep roadway affected by mining," Journal of China Coal Society, vol. 41, no. 1, pp. 246-254, 2016.

[9] F. L. He and G. C. Zhang, "Asymmetric failure and control measures of large cross-section entry roof with strong mining disturbance and fully-mechanized caving mining," Chinese Journal of Rock Mechanics and Engineering, vol. 35, no. 6, pp. 806-818, 2016.

[10] F. L. He and G. C. Zhang, "Deformation and failure mechanism and control technology of large section coal roadway subjected to severe mining dynamic load," Journal of Mining and Safety Engineering, vol. 33, no. 3, pp. 423-440, 2016.

[11] J. Zhang, L. Wang, Q. Li, and S. Zhu, "Plastic zone analysis and support optimization of shallow roadway with weakly cemented soft strata," International Journal of Mining Science and Technology, vol. 25, no. 3, pp. 395-400, 2015.

[12] Q. Wang, R. Pan, B. Jiang et al., "on failure mechanism of roadway with soft rock in deep coal mine and confined concrete support system," Engineering Failure Analysis, vol. 81, pp. 155-177, 2017.

[13] H. B. Li, X. Xia, J. C. Li, J. Zhao, B. Liu, and Y. Q. Liu, "Rock damage control in bedrock blasting excavation for a nuclear power plant," International Journal of Rock Mechanics and Mining Sciences, vol. 48, pp. 210-218, 2017.

[14] Y. Kang, Q. Liu, G. Gong, and H. Wang, "Application of a combined support system to the weak floor reinforcement in deep underground coal mine," International Journal of Rock Mechanics and Mining Sciences, vol. 71, pp. 143-150, 2014.

[15] G. Chen and S. L. Huang, "Analysis of ground vibrations caused by open pit production blasts? a case study," Fragblast, vol. 5, no. 1-2, pp. 91-107, 2001.

[16] E. Huang, M. Ataei, H. Hashemolhosseini, and H. Hosseini, "Development of a fuzzy model for predicting ground vibration caused by rock blasting in surface mining," Journal of Vibration and Control, vol. 19, no. 5, pp. 755-770, 2013.

[17] H. Dehghani and M. Ataee-Pour, "Development of a model to predict peak particle velocity in a blasting operation," International Journal of Rock Mechanics and Mining Sciences, vol. 48, no. 1, pp. 51-58, 2011.

[18] P. K. Singh, M. P. Roy, R. K. Paswan, R. K. Dubey, and C. Drebenstedt, "Blast vibration effects in an underground mine caused by open-pit mining," International Journal of Rock Mechanics and Mining Sciences, vol. 80, no. 8, pp. 79-88, 2015.

[19] A. Kahriman, "Evaluation of ground vibration due to surface blasting at a celestite open-pit mine," Fragblast, vol. 5, no. 1-2, pp. 21-34, 2001.

[20] Q. Wang, R. Pan, B Jiang et al., "Study on failure mechanism of roadway with soft rock in deep coal mine and confined concrete support system," Engineering Failure Analysis, vol. 81, 2017.

[21] F. T. Wang, S. F. Zhang, X. Wei, and S. Guo, "Whole section anchor-grouting reinforcement technology and its application in underground roadways with loose and fractured surrounding rock," Tunnelling and Underground Space Technology, vol. 51, pp. 133-143, 2016.

[22] F. J. Zhang, P. Liu, X. R. Meng, and Z. N. Gao, "Research of bearing mechanism of double support structure of deep soft rock roadway," Advanced Materials Research, vol. 734-737, pp. 606-613, 2013.

[23] X. M. Sun, G. F. Zhang, F. Cai, and S. Yu, "Asymmetric deformation mechanism within inclined rock strata induced by excavation in deep roadway and its controlling countermeasures," Chinese Journal of Rock Mechanics and Engineering, vol. 28, no. 6, pp. 1137-1143, 2009, in Chinese.

[24] M. Ramulu, A. K. Chakraborty, and T. G. Sitharam, "Damage assessment of basaltic rock mass due to repeated blasting in a railway roadwaying project: a case study," Tunnelling and Underground Space Technology, vol. 24, no. 2, pp. 208-221, 2008.

[25] Q. Chang, H. Zhou, Z. Xie, and S. Shen, "Anchoring mechanism and application of hydraulic expansion bolts used in soft rock roadway floor heave control," International 
Journal of Mining Science and Technology, vol. 23, no. 3, pp. 323-328, 2013.

[26] F. Gao, D. Stead, and H. Kang, "Numerical simulation of squeezing failure in a coal mine roadway due to mining-induced stresses," Rock Mechanics and Rock Engineering, vol. 48, no. 4, pp. 1635-1645, 2015.

[27] P. K. Singh, "Blast vibration damage to underground coal mines from adjacent open-pit blasting," International Journal of Rock Mechanics and Mining Sciences, vol. 39, no. 8, pp. 959-973, 2002.

[28] B. Shen, "Coal mine roadway stability in soft rock: a case study," Rock Mechanics and Rock Engineering, vol. 47, no. 6, pp. 2225-2238, 2014.

[29] W. J. Wang, Y. Yuan, W. J. Yu, and X. Chen, "Failure mechanism of the subinclined shaft in floor under mining influence and its control," Journal of China Coal Society, vol. 39, no. 8, pp. 1463-1472, 2014.

[30] X. S. Liu, Study on the Mechanism and Control of Rockburst in Roadways under Dynamic Loads, Shandong University of Science and Technology, Qingdao, China, 2017.

[31] K. Petr and W. Petr, "Stress changes and seismicity monitoring of hard coal longwall mining in high rockburst risk areas," Tunnelling and Underground Space Technology, vol. 81, pp. 237-251, 2018.

[32] S. Q. Yang, M. Chen, Y. H. Huang, H. W. Jing, and P. G. Ranjith, "An experimental study on fracture evolution mechanism of a non-persistent jointed rock mass with various anchorage effects by DSCM, AE and X-ray CT observations," International Journal of Rock Mechanics and Mining Sciences, vol. 134, Article ID 104429, 2020.

[33] S. Q. Yang, M. Chen, and Y. Tao, "Experimental study on anchorage mechanical behavior and surface cracking characteristics of a non-persistent jointed rock mass," Rock Mechanics and Rock Engineering, vol. 2021, pp. 1-29, 2021.

[34] S. J. Chen, D. W. Yin, N. Jiang, F. Wang, and W. J. Guo, "Simulation study on effects of loading rate on uniaxial compression failure of composite rock-coal layer," Geomechanics and Engineering, vol. 17, no. 4, pp. 333-342, 2019.

[35] J. He, "Research of mining dynamic loading effect and its induced rock burst in coal mine," Doctoral dissertation, China University of Mining and Technology, Xuzhou, China, 2013.

[36] M. Chen, S. Q. Yang, P. G. Ranjith, and Y. C. Zhang, "Cracking behavior of rock containing non-persistent joints with various joints inclinations," Theoretical and Applied Fracture Mechanics, vol. 109, Article ID 102701, 2020. 